\title{
EDITORIAL
}

\section{Recesión económica y Salud Pública}

La recesión económica mundial sigue acaparando los espacios noticiosos en Chile y en todo el planeta. Al principio las informaciones eran, fundamentalmente, de carácter bastante técnico y se relacionaban con la volatilidad de los mercados, la debilidad de los instrumentos de intercambio y la merma en los indicadores sectoriales, entre muchos otros. Pero en los últimos días, voces de alarma generalizada han estado apuntando a problemas mucho más humanos $\mathrm{y}$, por tanto, mucho más cercanos a la vida del ciudadano medio. El desempleo surge como la primera y más directa consecuencia de la recesión económica y que, a la vez, tiene un impacto inmediato sobre la salud y calidad de vida de las personas, familias y comunidades. Así, por ejemplo, la Organización para la Cooperación y el Desarrollo Económico (OCDE), que incluye las economías más desarrolladas del mundo, proyecta que la tasa de desempleo promedio entre sus países miembros pasará del $6 \%$ en 2008 al 8,4\% en 2009 y al $9,9 \%$ en el 2010.

En Chile se reportan cifras que indican una desaceleración generalizada de la actividad económica y, en algunos sectores, un virtual estancamiento. La Sociedad de Fomento Fabril (SOFOFA), por ejemplo, reporta un decrecimiento de la actividad industrial de un 10 por ciento y un 8.1 por ciento de caída en las ventas a diciembre 2008. Por su parte, el Instituto Nacional de Estadísticas (INE) informa que la tasa de desempleo ascendió a un 8 por ciento en el trimestre noviembre-enero, superando la tasa del mismo período anterior de 7,2 por ciento. Tanto la baja en los índices de productividad como de empleo están indicando que nuestro país, lejos de ser inmune a la crisis mundial, está recibiendo gradualmente su impacto. Pero aún más dramática es la baja generalizada de los fondos de pensiones de todos los chilenos con tasas que van desde un 5 hasta un 30 por ciento. Por tanto a la actual inseguridad respecto del empleo se suma la preocupación por la futura jubilación.

La Salud Pública no es ajena a la crisis económica mundial. Por el contrario, se ve afectada directa y dramáticamente por ella. Como corresponde, los salubristas están haciendo sonar las alarmas en todo el mundo respecto a esta situación. La profundización de la crisis, con sus secuelas de desempleo, erosión de ahorros y fondos de pensión, fallas en las redes de protección social y caída del gasto público, no puede sino producir o empeorar problemas de salud en las personas. De la misma manera, organismos internacionales están expresando sus temores en relación a diversos aspectos de la salud. El propio Director del Fondo Monetario Internacional (FMI) ha advertido que la recesión es "una aguda erosión en la Salud Pública debido a que el paciente, ahogado financieramente, se ve forzado a postergar sus tratamientos". Por su parte, la Comisionada de Salud de la Unión Europea instó a sus colegas de los 27 estados miembros a dar "cuidadoso seguimiento a la evolución de la situación sanitaria y social" durante el período de crisis económica.

La crisis que se originó en los países ricos eventualmente afectará más agudamente a los países pobres. El Programa de Naciones Unidades para los Asentamiento Humanos (ONU-Habitat), declaró en su último encuentro de Nairobi que el número de personas que vive en entornos no saludables podría duplicarse en el mediano plazo si no se toman medidas para mitigar los efectos de la crisis en los países más pobres. Pero, además del impacto social, la crisis también tiene un efecto en el comportamiento de las personas. Salubristas en países pobres y ricos están expresando preocupación por el posible aumento en el uso de tabaco, alcohol y otras drogas debido al impacto de la crisis en la salud mental de las personas como lo han demostrado estudios de crisis anteriores.

La Dra. Margaret Chan, Directora General de la Organización Mundial de la Salud (OMS), recientemente llamó a una reunión consultiva urgente para analizar la respuesta del sector salud a la 
crisis económica. Allí se planteó que los salubristas debemos proteger a la población adelantándonos a los efectos negativos en la salud de las personas y, utilizando las experiencias del pasado, buscar "entender lo mejor posible qué puede ocurrir, qué señales de alerta podemos esperar, cuándo intervenir y qué medidas tomar." Asimismo, debemos defender, con argumentos convincentes, la financiación de la atención y la promoción de la salud generalmente vulnerable a los cortes en el gasto social de los gobiernos. Debemos recordar que en épocas de estrechez financiera la gente tiende a migra de los servicios privados a los públicos abultando la demanda al ya recargado y mal financiado sector público.

En nuestro Chile, urge que todo el sector salud, encabezado por nuestras autoridades, nos planteemos estrategias para impedir o, al menos, mitigar los peores efectos de la crisis mundial en la salud de nuestro pueblo. Las recomendaciones de OMS son plenamente aplicables en nuestro país: no reducir porcentaje PBI en salud; priorizar grupos vulnerables; trabajar en los determinantes sociales; trabajar hacia un sistema de cobertura universal y monitorear la evolución de la crisis respecto a sus efectos en la salud. El momento de comenzar es hoy.

Leonel A. Valdivia

Jefe División de Promoción de la Salud

Escuela de Salud Pública 